\title{
Prenatal diagnosis of a giant intracranial teratoma associated with pulmonary hypoplasia
}

\author{
Leah K Weyerts, Val Catanzarite, Marilyn C Jones, Arturo Mendoza
}

Division of Genetics, Department of Pediatrics, East Carolina University School of Medicine, Brody 3E-140, Greenville, NC 27858, USA.

L K Weyerts

Maternal-Fetal Medicine and Perinatal Pathology, Mary Birch Hospital for Women at Sharp Memorial Hospital, San Diego, CA, USA. V Catanzarite

A Mendoza

Division of Dysmorphology, Children's Hospital of San Diego, San Diego, CA, USA

M C Jones

Correspondence to Dr Weyerts.

Received 26 February 1993 Revised version accepted 13 April 1993.

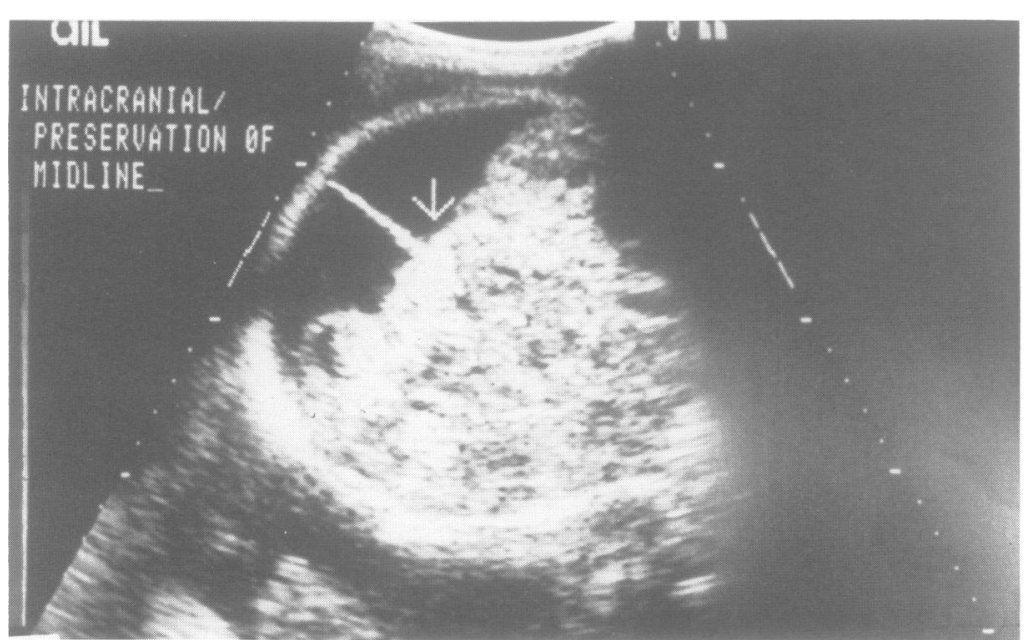

Figure 1 Ultrasound at 31 weeks' gestation. In this coronal view, the cystic component of the tumour filling the upper portion of the cranial vault, and the solid component below, are clearly seen.

\begin{abstract}
We present a case in which an intracranial tumour replacing all intracranial contents was diagnosed by sonography at 31 weeks' gestation. The patient was delivered by caesarean section and died shortly after delivery. At necropsy, the tumour was found to be a teratoma with no recognisable normal brain tissue present. Additional findings at necropsy included pulmonary and adrenal hypoplasia. The diagnosis and prognosis of intracranial teratomas diagnosed in utero, and the association of this tumour with pulmonary hypoplasia, are discussed.

(F Med Genet 1993;30:880-2)
\end{abstract}

Teratomas are the most common intracranial neoplasms occurring in utero, but are very rare; only about 20 cases have been diagnosed in utero. ${ }^{1-7}$ In most of these cases, sonographic evaluation was prompted in the late second trimester or third trimester by sudden acceleration in the growth of the uterus in a previously uncomplicated pregnancy. ${ }^{45}$ Sonographic findings range from hydrocephalus in association with an intracranial mass to macrocephaly with apparent replacement of normal intracranial structures with disorganised solid and cystic tumour masses; extracranial extension has also been reported. ${ }^{7}$ With rare exceptions, intracranial teratomas diagnosed in utero have fatal outcomes. Here, we present a case in which a massive intracranial tumour, presumed to be a teratoma, was diagnosed in utero. The fetus was found at delivery to have pulmonary hypoplasia. We speculate that destruction of midbrain centres controlling reswere replaced by tumour. The lower two thirds of the cranial cavity was filled with a 'bubbly' appearing solid mass; in the upper third two large cystic structures were present, one on each side of the midline, when the head was viewed in coronal section (fig 1). There were no large areas of calcification, but a variegated pattern of echodensities within the 'bubbly' component was felt to be consistent with numerous small calcifications.

Anatomical visualisation was limited owing to the fetal position, but normal anatomy of the spine, heart, kidneys, liver, and extremities was seen. The stomach bubble was not seen despite favourable orientation of the fetus during the scan. The bladder and genitalia could not be seen because of breech presentation. No fetal movement was present.

The diagnosis of an intracranial tumour, probably a teratoma, was made. Because of 
increasing maternal discomfort, delivery was planned within the next week. Owing to the size and predominantly solid nature of the mass, as well as the breech presentation, delivery was by classical caesarean section (fig 2). The infant was bradycardic at delivery, had no spontaneous respirations, and was pronounced dead 25 minutes later.

At necropsy, the cranium was massively enlarged and completely filled with a soft, haemorrhagic appearing mass. No normal brain architecture was identified. All three germ layers were represented within the mass, confirming the diagnosis of intracranial teratoma (fig 3). There was no extracranial extension of the tumour.

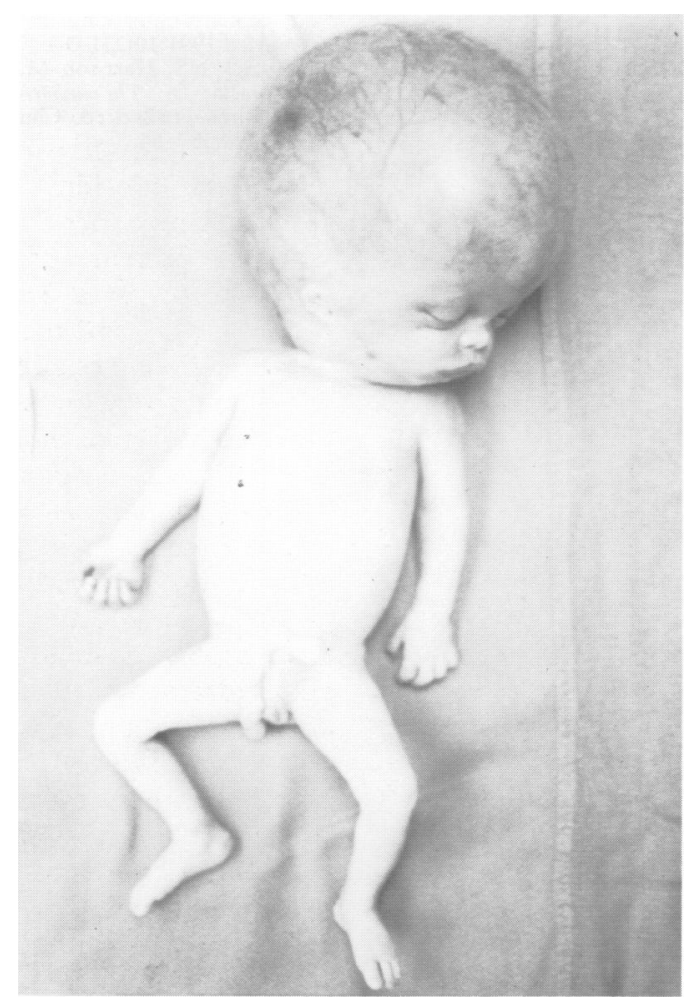

Figure 2 The infant at birth.



Figure 3 Photomicrograph of a section of the teratoma showing cartilage, neural tissue, smooth muscle, mixed mucinous and serous epithelium, respiratory epithelium, and squamous epithelium.
A gestational age of $32 \cdot 5$ weeks was determined by foot length measurement $(6 \cdot 3 \mathrm{~cm})$. In addition to the intracranial pathology, a diffusely enlarged liver ( $178 \mathrm{~g}$, normal $76 \mathrm{~g}$ ), small adrenals $(1.6 \mathrm{~g}$, normal $5.0 \mathrm{~g})$, and hypoplastic lungs ( $24 \mathrm{~g}$, normal $38 \pm 10 \mathrm{~g}$ ) were noted. Microscopic examination showed reduced radial alveolar counts, confirming the diagnosis of pulmonary hypoplasia.

The placenta was large ( $570 \mathrm{~g}$, normal 290 to $320 \mathrm{~g}$ ) and spongy. Microscopic examination showed diffuse chorionic villus oedema and pigmented macrophages within the amnion. Chorionic villus oedema has been reported in association with sacrococcygeal teratomas, but not with intracranial teratomas. The fetus and the teratoma both had $46, \mathrm{XX}$ chromosome complements, with identical pericentromeric markers.

The mother has subsequently had a term delivery of a normal infant.

\section{Discussion}

Teratomas are the most common fetal tumours, with intracranial teratomas second in frequency only to sacrococcygeal teratomas. ${ }^{8-10}$ Teratomas represent half of all neonatal intracranial neoplasms. ${ }^{4}$

There are 20 previous reports of prenatal diagnosis of intracranial teratomas ${ }^{1-7}$ and among these there was only one survivor. This infant had complete resection of a malignant intracranial teratoma, but has severe intellectual impairment. ${ }^{5}$ The sonographic diagnosis of intracranial teratoma has usually occurred in the setting of rapid increase in the fundal height during the late second and third trimester; sonography shows polyhydramnios and either macrocephaly with a large intracranial tumour, or hydrocephalus and a mass lesion. In cases with diagnosis several weeks before delivery, increase in the size of the mass and of the fetal head has been dramatic. ${ }^{2}$

The differential diagnosis of fetal intracranial masses includes teratoma, neuroectodermal tumours, astrocytomas, glioblastoma multiform, and choroid plexus papilloma. ${ }^{6}$ Additionally, there has been one report in which intracranial teratoma was suspected, but the fetus proved to have evolving hydranencephaly. ${ }^{11}$ There have only been a handful of sonographic diagnoses of intracranial tumours other than teratomas in utero, ${ }^{1}$ and differentiation of teratoma from other tumours cannot currently be made with certainty until after delivery.

Extracranial abnormalities noted at necropsy in cases of congenital intracranial teratomas have not been well described. In the present case, extracranial features included hepatomegaly, adrenal hypoplasia, and pulmonary hypoplasia. Odell et $a l^{2}$ described 'congestive hepatomegaly' in one case and 'pulmonary immaturity' in the other. The degree of pulmonary hypoplasia seen in this case has not been described before.

Proposed mechanisms of the pathogenesis of pulmonary hypoplasia include extrinsic restraint, through space occupying lesions such 
as in diaphragmatic hernia, lack of amniotic fluid as in prolonged oligohydramnios, and lack of fetal breathing movements such as in the fetal akinesia sequence. ${ }^{12}$ It is believed that not only the presence of amniotic fluid, but also movement of the fetal diaphragm, is necessary for normal lung growth. In the case presented here, we speculate that damage or destruction of the central control mechanisms for fetal breathing occurred well before the clinical presentation and resulted in lung hypoplasia through lack of movement of the diaphragm. The adrenal hypoplasia would also be consistent with early destruction of pituitary tissue as this is a common feature in anencephalic infants.

Intracranial teratomas diagnosed in utero have an almost uniformly fatal outcome. This case shows the rapidly destructive nature of these tumours as the pituitary and brainstem functions appear to have been affected before clinical symptoms appeared.
1 Wienk MATP, Van Geijn HP, Copray FJA, Brons JTJ. Prenatal diagnosis of fetal tumors by ultrasonography.

2 Odell JM, Allen JK, Badura RJ, Weinberger E. Massive congenital intracranial teratoma. Pediatr Pathol 1987;7:333-40.

3 Dolkart LA, Balcom RJ, Eisenger G. Intracranial teratoma: prolonged neonatal survival after prenatal diagnosis. $\mathrm{Am}$ f Obstet Gynecol 1990;162:768-9.

4 Lipman SP, Pretorius DH, Rumack CM, Manco-Johnson ML. Fetal intracranial teratoma: ultrasound diagnosis of three cases and a review of the literature. Radiology 1985;157:491-4.

5 Oi S, Tamaki N, Kondo T, et al. Massive congenital intracranial teratoma diagnosed in utero. Childs Nerv Syst 1990;6:459-61.

6 Kwoon T, Jeanty P. Cystic teratoma. The Fetus 1990;1:7-9.

7 Rostad S, Kleinschmidt-DeMasters BK, Manchester DK. Two massive congenital intracranial immature teratomas with neck extension. Teratology 1985;32:163-9.

8 wamura H, Kury G, Suzuki K. Intracranial teratomas in fetal life and infancy. Obstet Gynecol 1966;27:134-41.

9 Ventureyra E, Herder $S$. Neonatal intracranial teratoma. $\mathcal{f}$ Neurosurg 1983;59:879-83.

10 Nanda A, Scchut L, Sutton L. Congenital forms of intracranial teratoma. Childs Nerv Syst 1991;7:112-14.

11 Belfar H, Kuller J, Hill L, Kislak S. Evolving fetal hydrencephaly mimicking intracranial neoplasm. $\mathcal{f}$ Ultrasound Med 1991;10:231-3.

12 Adzick NS, Harrison M. Experimental pulmonary hypoplasia. In: The unborn patient: prenatal diagnosis and treatment. 2nd ed. Chapter 48. Philadelphia: Saunders, 1990:557-64. 